\title{
Efisiensi Pendayagunaan Tempat Tidur dengan Metode Grafik Barber- Johnson di Rs Lancang Kuning
}

\author{
Bed Utilization Efficiency With Graphic Of Barber-Johnson Method In \\ Lancang Kuning Pekanbaru Hospital Year 2011
}

\author{
Edi Susilo* Nopriadi**
}

*PIKES STIKes Hang Tuah Pekanbaru, **PSIKM Fakultas Kedokteran UNAND

\begin{abstract}
ABSTRAK
Pendayagunaan tempat tidur di rumah sakit seharusnya efisien dari aspek ekonomi maupun aspek medis. Untuk menyatukan dua aspek tersebut maka diperlukan suatu parameter yang tepat, yaitu; BOR, AvLOS, TOI, dan BTO. Menyajikan keempat parameter tersebut dapat digunakan suatu metode yaitu grafik barber-johnson, dimana kita dapat melihat tingkat efisiensi pendayagunaan tempat tidur di rumah sakit dengan jelas dan keempat parameter dipertemukan dalam satu titik. Penelitian ini bertujuan untuk menilai tingkat efisiensi pendayagunaan tempat tidur di RS Lancang Kuning Pekanbaru tahun 2011. Penelitian ini menggunakan jenis penelitian deskriptif. Populasi penelitian ini adalah formulir (RP 1 dan RL 1) periode tahun 2011, pengambilan sampel dengan menggunakan teknik total sampling. Teknik pengumpulan data menggunakan observasi dan dokumentasi, analisis data dilakukan secara univariat. Dari hasil penelitian ditemukan bahwa pendayagunaan tempat tidur di RS Lancang Kuning Pekanbaru tahun 2011 dengan metode grafik BJ titik keempat parameter tidak bertemu pada satu titik melainkan terpisah 2 bagian, angka (AvLOS 8 hari dan TOI 11 hari) sedangkan (BOR 50\% dan BTO 15 kali). Hal ini kemungkinan disebabkan adanya kasalahan dalam sensus harian pasien rawat inap yang menjadi sumber data primer. Temuan ini diperkuat dengan tidak berjalannya sensus harian pasien rawat inap di RS Lancang Kuning Pekanbaru dengan baik. Selain itu, bila dilihat dari masing-masing titik parameter dalam grafik BJ berada di luar daerah efisien yang berarti menunjukan sistem yang berjalan kurang baik. Kesimpulan penelitian ini adalah bahwa pendayagunaan tempat tidur di RS Lancang Kuning Pekanbaru pada tahun 2011 masih kurang efisien. Disarankan agar pihak manajemen mengevaluasi akan kurangnya permintaan tempat tidur dan unit rekam medis agar menjalankan kegiatan sensus harian pasien rawat inap sesuai dengan ketentuan.
\end{abstract}

Kata Kunci : Efisiensi Pendayagunaan Tempat Tidur, Grafik Barber-Johnson

\begin{abstract}
Utilization Utilization of hospital beds should be efficient not only economic but also medical aspects. To unify these two aspects, we need a proper parameter, namely, BOR, AvLOS, TOI, and BTO. To present these four parameter, it can used the method of barber-johnson chart, where we can see the efficiency of utilization of hospital beds and four parameter clearly brought together in one spot. This study aims to assess the efficiency of utilization of hospital beds in Lancang Yellow Pekanbaru in 2011. This research uses descriptive research. This is the form the study population (RP 1 and RL 1$)$ the period of 2011, sampling by using total sampling technique. Data collection technique used observation and documentation, analysis technique are univariat. From the research, it was found that the utilization of hospital beds in Lancang Yellow Pekanbaru in 2011 by BJ graphical method parameters do not meet the four points at one point but separated two parts, numbers (TOI AvLOS 8 days and 11 days) while (BOR 50\% and 15 BTO times). This is probably caused by the error of the daily census of inpatients who become the primary data source. This finding is reinforced by the ineffectiveness of the daily census of inpatients in hospitals Pekanbaru Yellow Lancang. In addition, when viewed from each point in the graph, BJ parameter is outside the area which indicates the running system is poor. Conclusions of this study is utilization of hospital beds in Lancang Yellow Pekanbaru in 2011, it is still less efficient. It is suggested to the hospital management to evaluate the lack of bed and medical records unit in order to execute activities of daily census of inpatients in accordance with the provisions.
\end{abstract}

Keywords: Utilization Efficiency Beds, Graph Barber-Johnson

\section{PENDAHULUAN}

Pembangunan kesehatan adalah bagian dari pada pembangunan nasional merupakan salah satu upaya dari bangsa Indonesia untuk mencapai kemampuan hidup sehat bagi setiap penduduk
(Brotowarsito, 2003). Untuk mencapai itu maka suatu sarana pelayanan kesehatan (rumah sakit) harus memberikan pelayanan kesehatan yang bermutu dan melaksanakan upaya kesehatan secara berdaya dan berhasil guna (Aditama, 2010). 
Pencatatan data medik yang berkenaan dengan penyelenggaraan pelayanan kepada pasien mutlak perlu bagi rumah sakit. Unit Rekam Medis dituntut untuk melaksanakan pencatatan medik yang akurat, salah satunya adalah menghitung pendayagunaan tempat tidur terhadap empat parameter. Dari aspek ekonomi, pihak manajemen menginginkan agar setiap tempat tidur yang telah disediakan salalu terisi dan digunakan oleh pasien, jumlah tempat tidur yang kosong atau "menganggur" diharapkan sesedikit mungkin. Dari aspek medis terjadi arah penilaian yang bisa berlawanan, Tim Medis akan lebih senang dan merasa berhasil kerjanya jika seorang pasien bisa segara sembuh sehingga tidak perlu dirawat, jadi tidak menggunakan tempat tidur terlalu lama.

Dengan adanya dua sudut pandang yang berlawanan ini maka diperlukan cara yang lebih tepat untuk menggambarkan efisiensi pendayagunaan tempat tidur di rumah sakit. Dibutuhkan kriteria atau parameter yaitu Bed Occupancy Rate (BOR), Average Length Of Stay (AvLOS), Turn Over Interval (TOI), dan Bed Turn Over (BTO). Untuk melihat keempat parameter tersebut dapat disajikan dalam bentuk grafik Barber-Johnson (BJ). Pembuatan grafik BJ sangat diperlukan karena manajemen rumah sakit dapat memonitor kegiatan dalam waktu tertentu, dapat menyajikan secara visual sekaligus empat variabel rumah sakit dan menyusun rencana untuk peningkatan efisiensi pelayanan rumah sakit (Sudra, 2010).

RS Lancang Kuning Pekanbaru mempunyai 4 ruang rawat inap yaitu; Anggrek, Cendrawasih, Intensive Care Unit (ICU), dan Kebidanan, yang keseluruhannya mempunyai 98 tempat tidur pada akhir tahun 2011. Menurut hasil observasi awal penulis, pada akhir tahun 2010 jumlah tempat tidur sebanyak 78 buah angka BOR 43\%, AvLOS 9 hari, TOI 12 hari, dan BTO 14 kali. Dari data tersebut kita dapat simpulkan bahwa pendayagunaan tempat tidur masih belum efisien. Menurut Dep.Kes (2005) efisiensi pendayagunaan tempat tidur apabila angka BOR berkisar antara 65-85\%, AvLOS 6-9 hari, TOI 13 hari, dan BTO 40-50 kali dalam setahun.

Tujuan dari penelitian ini adalah untuk mengetahui gambaran umum tingkat efisiensi pendayagunaan tempat tidur dengan metode grafik BJ di RS Lancang Kuning Pekanbaru tahun 2011.

\section{METODE}

Jenis penelitian ini adalah penelitian deskriptif yang bertujuan untuk memperoleh gambaran tentang keadaan secara obyektif mengenai efisiensi pendayagunaan tempat tidur dengan menggunakan grafik BJ di RS Lancang Kuning Pekanbaru, yang berguna sebagai bahan evaluasi oleh pihak manajemen. Populasi dan sampelnya adalah lembar formulir rekapitulasi sensus pasien rawat inap bulanan
(RP 1 dan RL 1) dengan menggunakan teknik total sampling.

\section{HASIL}

Pendayagunaan Tempat Tidur (BOR, AVLOS, BTO dan TOI) di RS Lancang Kuning Pekanbaru Tahun 2011

Tabel 1

Data Pendayagunaan Tempat Tidur di RS Lancang Kuning Pekanbaru Tahun 2011

\begin{tabular}{clc}
\hline No & Indikator & Keterangan \\
\hline 1 & Tempat tidur & 82 buah \\
\hline 2 & BOR & $50 \%$ \\
\hline 3 & AvLOS & 8 hari \\
\hline 4 & TOI & 11 hari \\
\hline 5 & BTO & 15 kali \\
\hline
\end{tabular}

Tabel $1 \mathrm{di}$ atas merupakan data yang diperoleh dari formulir rekapitulasi sensus harian rawat inap (RP 1), dengan uraian sebgai berikut:

Jumlah hari perawatan $=14628$ hari

Pasien masuk $=1535$ pasien

Pasien keluar (hidup dan mati) $=1439$ pasien

Jumlah Lama dirawat $=11396$ hari

Jumlah tempat tidur $=82$ buah

Periode 1 tahun $(2011)=365$ hari.

Efisiensi Pendayagunaan Tempat Tidur dengan Menggunakan Grafik BJ Di RS Lancang Kuning Pekanbaru Tahun 2011

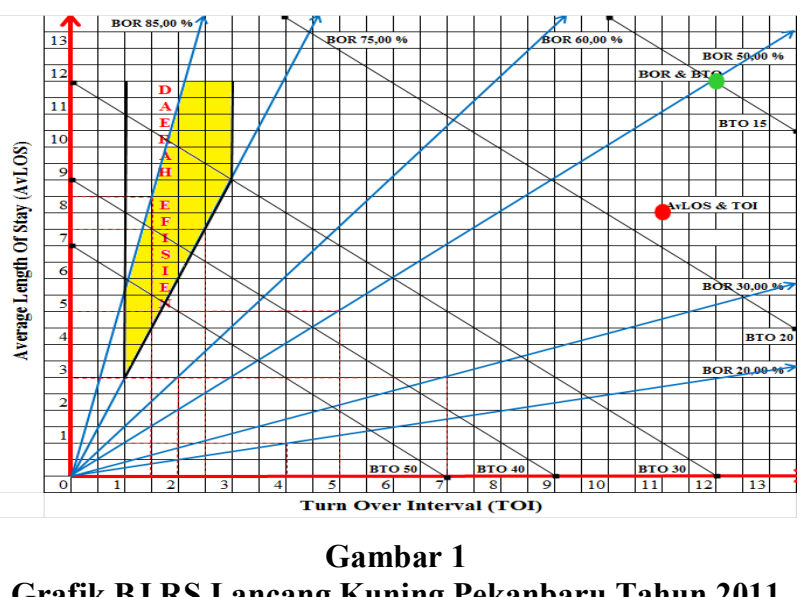

Grafik BJ RS Lancang Kuning Pekanbaru Tahun 2011

Keterangan gambar :

- Titik temu AvLOS dan TOI (8 hari dan 11 hari) Titik temu BOR dan BTO (50\% dan 15 kali) 
Perkembangan Tingkat Efisiensi Pendayagunaan Tempat Tidur di RS Lancang Kuning Pekanbaru dari Bulan Januari Sampai Desember Tahun 2011 dengan Metode Grafik BJ

Tabel 2

Pendayagunaan Tempat Tidur di RS Lancang Kuning Pekanbaru Periode Januari-Desember Tahun 2011

\begin{tabular}{lrccc}
\hline \multicolumn{1}{c}{ BULAN } & BOR & ALOS & TOI & BTO \\
\hline Januari & 40 & 8 & 12 & 2 \\
\hline Februari & 38 & 8 & 17 & 1 \\
\hline Maret & 43 & 9 & 12 & 1 \\
\hline April & 46 & 6 & 10 & 1 \\
\hline Mei & 53 & 7 & 10 & 1 \\
\hline Juni & 58 & 7 & 8 & 1 \\
\hline Juli & 51 & 9 & 8 & 1 \\
\hline Agustus & 40 & 6 & 14 & 1 \\
\hline September & 43 & 7 & 12 & 1 \\
\hline Oktober & 48 & 5 & 6 & 2 \\
\hline Nopember & 59 & 8 & 5 & 2 \\
\hline Desember & 56 & 7 & 11 & 1 \\
\hline
\end{tabular}

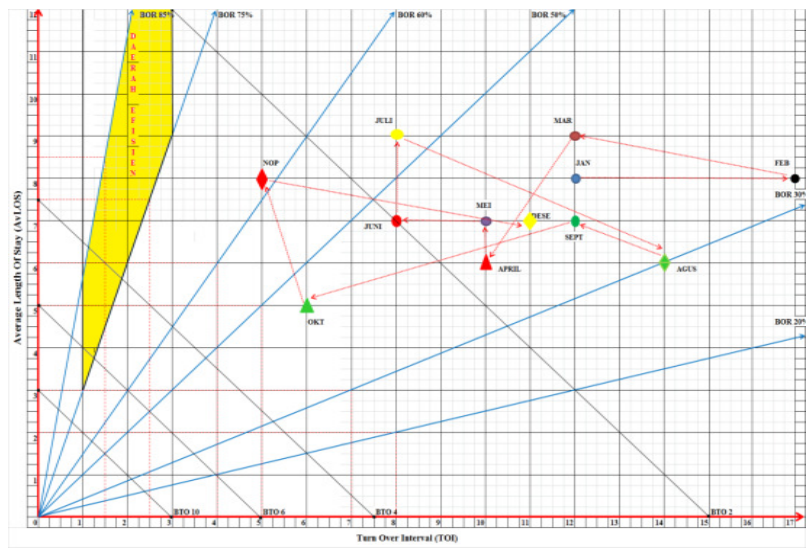

Gambar 2

Grafik BJRS Lancang Kuning Pekanbaru Periode Bulan Januari Desember Tahun 2011

Keterangan gambar (BOR, AvLOS, TOI, dan BTO) :

- Januari $(40,8,12$, dan 2$)$

- Februari $(38,8,17$, dan 1)

- Maret $(43,9,12$, dan 1$)$

- April $(46,6,10$, dan 1)

- $\operatorname{Mei}(53,7,10$, dan 1$)$

- Juni $(58,7,8$, dan 1$)$

Juli $(51,9,8$, dan 1$)$

Agustus (40, 6, 14, dan 1)

- September $(43,7,12$, dan 1$)$

$\triangle$ Oktober $(48,5,6$, dan 2)

$\checkmark$ Nopember $(59,8,5$, dan 2)

Desember (56, 7, 11, dan 1)

Perbandingan Tingkat Efisiensi Pendayagunaan Tempat Tidur di RS Lancang Kuning Pekanbaru Tahun 2011 Antar Ruang Rawat Inap dengan Metode Grafik BJ
Di RS Lancang Kuning Pekanbaru kegiatan sensus harian pasien rawat inap tidak dilakukan oleh perawat ruangan melainkan oleh petugas rekam medis yang mendapatkan laporan dari perawat atau dengan melihat buku register yang ada di ruang rawat inap. Tapi terkadang data yang termuat dalam buku register yang ada di ruang rawat inap tidak dapat memenuhi kelengkapan item-item yang ada di sensus harian pasien rawat inap seperti kelas perawatan, jadi petugas harus melihat kembali ringkasan masuk dan keluar pada file pasien yang bersangkutan yang filenya sudah tersimpan di ruang penyimpanan berkas.

Tidak cukup sampai disini, berkas rekam medis terkadang juga tidak ada di ruang penyimpanan karena adanya keterlambatan pengembalian berkas oleh ruang rawat inap. Setelah data dari ruangan didapatkan oleh petugas rekam medis, kemudian petugas yang bersangkutan merekap seluruh pasien dari ruangan per hari berdasarkan pasien masuk dan pasien keluar.

RS Lancang Kuning Pekanbaru mempunyai 4 ruang rawat inap yaitu; Anggrek, Cendrawasih, Intensive Care Unit (ICU), dan Kebidanan. Dari keempat ruangan tersebut, ruangan cendrawasih merupakan ruangan yang khusus untuk merawat pasien kejiwaan. Lamanya AvLOS seorang pasien dengan gangguan jiwa tentunya berdampak pula pada angka parameter yang lainnya (BOR, TOI, dan BTO) tentunya sudah jelas penggunaan tempat tidur di ruangan tersebut tidak efisien. Oleh karena itu, penulis ingin meneliti per ruang rawat inap yang ada. Walaupun sudah jelas tidak efisien, melihat penggunaan dengan metode grafik BJ sangat diperlukan karena berfungsi untuk mengecek kebenaran laporan. Untuk menghitung tingkat efisiensi penggunaan tempat tidur disuatu ruang rawat inap maka diperlukan sensus harian pasien rawat inap per ruangan yang dibuat oleh perawat masing-masing ruangan dan kemudian diserahkan kepada petugas rekam medis yang bertanggung jawab untuk dilakukan rekapitulasi.

\section{PEMBAHASAN}

Pendayagunaan Tempat Tidur (BOR, AVLOS, BTO dan TOI) di RS Lancang Kuning Pekanbaru Tahun 2011

\section{Bed Occupancy Ratio (BOR)}

Tempat tidur hanya terpakai/digunakan separuhnya dari tempat tidur yang tersedia pada tahun 2011 atau 50\% dari 82 tempat tidur. Menurut DepKes RI (2005) Nilai parameter dari BOR ini idealnya adalah antara 60-85\%. Jadi dengan kapasitas 82 tempat tidur yang ada pada tahun 2011 maka tempat tidur yang harus digunakan adalah sebanyak 49-70, agar penggunaan tempat tidur pada periode tersebut efisien dari aspek medis maupun ekonomi. 
Hal tersebut menandakan bahwa pendayagunaan tempat tidur belum mencapai efisien dari segi ekonomi, dimana terjadi arah yang berlawanan dengan apa yang diharapkan oleh pihak manajemen. Pihak manajemen tentunya ingin tempat tempat tidur berhasil guna dan berdaya guna agar menghasilkan income bagi rumah sakit (Sudra, 2010).

\section{Average Length Of Stay (AvLOS)}

Rata-rata seorang pasien dirawat di RS Lancang Kuning Pekanbaru mencapai 8 hari. Contohnya; jika seorang pasien masuk pada tanggal 1 januari 2011, maka pasien tersebut akan meninggalkan rumah sakit pada tanggal 8 januari 2011. Menurut DepKes RI (2005) AvLOS yang ideal antara 6-9 hari. Ini menunjukan bahwa rata-rata untuk perawatan seorang pasien di RS Lancang Kuning Pekanbaru sudah efisien baik dari segi medis maupun ekonomis.

\section{Turn Over Interval (TOI)}

Sebuah tempat tidur di RS Lancang Kuning Pekanbaru mulai dari tempat tidur tersebut ditinggalkan oleh pasien sampai tempat tidur ditempati lagi oleh pasien lainnya (tempat tidur menganggur) mencapai 11 hari. Menurut DepKes RI (2005) Idealnya tempat tidur kosong hanya dalam waktu 1-3 Hari. Hal ini tentu belum efisien dari aspek ekonomi, karena lamanya waktu tempat tidur tidak ditempati. Pihak manajemen menginginkan agar setiap tempat tidur yang telah disediakan selalu terisi dan digunakan oleh pasien, jumlah tempat tidur yang kosong atau "menganggur" diharapkan sesedikit mungkin. Tempat tidur yang disediakan tentu akan memerlukan perawatan yang membutuhkan cost (biaya). Semakin lama seorang pasien menempati sebuah tempat tidur maka akan semakin banyak menghasilkan uang (Sudra, 2010).

\section{Bed Turn Over (BTO)}

Satu buah tempat tidur yang ada di RS Lancang Kuning Pekanbaru digunakan sebanyak 15 kali pada tahun 2011. BTO terlalu tinggi akan mengakibatkan tidak terjaminnya proses sterilisasi, yang kemungkinan bisa menyebabkan infeksi nosokomial. Menurut DepKes RI (2005) idealnya 4050 pasien dalam 1 tahun. Hal ini tentunya masih jauh dari ideal. Rendahnya BTO juga akan berdampak pada BOR dan TOI.

Pendayagunaan tempat tidur di RS Lancang Kuning Pekanbaru pada tahun 2011 secara keseluruhan masih belum ideal, kecuali AvLOS. Kurang efisiennya pendayagunaan tempat tidur akan membawa dampak ekonomi bagi rumah sakit itu sendiri, yakni akan berkurang pula pendapatan rumah sakit. Kurangnya permintaan tempat tidur yang mengakibatkan tingginya angka TOI, hal ini kemungkinan disebabkan oleh organisasi yang kurang baik, dan dapat dilakukan dengan melakukan perbaikan organisasi tanpa mempengaruhi LOS (Rustiyanto, 2010). Tempat tidur yang disediakan tentu akan membutuhkan cost (biaya) untuk perawatannya, sementara pendayagunaan tempat tidur tersebut belum maksimal/efisien untuk menghasilkan income. Hal ini tentunya perlu perhatian yang lebih bagi pihak manajemen agar lebih intensif dalam berbagai kebijakan yang dapat meningkatkan pemakaian tempat tidur, seperti kegiatan promotif.

\section{Efisiensi Pendayagunaan Tempat Tidur dengan Menggunakan Grafik BJ Di RS Lancang Kuning Pekanbaru Tahun 2011}

Grafik BJ pada gambar 1 tidak mempertemukan keempat indikator dalam pendayagunaan tempat tidur di rumah sakit. Dari grafik tersebut kita dapat melihat titik temu parameter yang ada di RS Lancang Kuning Pekanbaru tergambar terpisah dalam 2 bagian (BOR 50\% dan BTO 15 kali) sedangkan (AvLOS 8 hari dan TOI 11 hari). Menurut Soejadi (1996) salah satu fungsi dari grafik BJ adalah mengecek kebenaran suatu laporan, jadi apabila titik barber-johnson tidak berada dalam satu titik kemungkinan ada kesalahan dalam proses pembuatan pelaporan. Sedangkan menurut Sudra (2010) Jika perhitungan nilai keempat parameter tersebut benar (datanya benar, rumusnya benar, cara menghitungnya benar, dan pembulatannya benar) maka seharusnya keempat garis bantu itu akan berpotongan di satu titik.

Pendapat kemungkinan adanya kesalahan yang dikemukakan oleh beberapa literatur, semakin memperkuat temuan penulis bahwasanya di RS Lancang Kuning Pekanbaru sensus harian pasien rawat inap tidak berjalan sebagaimana yang semestinya. Dimana sensus merupakan sumber data primer dalam menghitung penggunaan tempat tidur dalam periode waktu tertentu, jadi seharusnya sumber data tersebut haruslah akurat, tepat, dan lengkap agar menghasilkan suatu informasi yang akurat pula.

Dalam grafik BJ pada gambar 2 masingmasing titik keempat parameter (BOR 50\% dan BTO 15 kali) serta (AvLOS 8 hari dan TOI 11 hari) tergambar di luar daerah efisien. Menurut Sudra (2010) dan Rustiyanto (2010) apabila titik parameter pendayagunaan tempat tidur tergambar di luar daerah efisien maka penggunaan tempat tidur di rumah sakit tersebut masih belum efisien/ideal dan menandakan bahwa sistem yang berjalan kurang baik. Dari temuan penulis bahwa pendayagunaan tempat tidur di RS Lancang Kuning Pekanbaru kurang efisien dari aspek ekonomi, dan akan berdampak pada pendapatan rumah sakit.

Perkembangan Tingkat Efisiensi Pendayagunaan Tempat Tidur Di RS Lancang Kuning Pekanbaru dari Bulan Januari sampai Desember Tahun 2011 dengan Metode Grafik BJ

a. Bulan Januari angka BOR 40\%, AvLOS 8 hari, TOI 12 hari, dan BTO 2 kali. Grafik tersebut 
menggambarkan bahwa penggunaan tempat tidur pada bulan Januari masih belum efisien, hal ini dapat dilihat pada titik temu keempat parameter terletak di luar daerah efisien/ideal.

Menurut Soejadi (1996), Sudra (2010), dan Rustiyanto (2010) apabila titik parameter pendayagunaan tempat tidur tergambar di luar daerah efisien maka penggunaan tempat tidur di rumah sakit dan pada periode tersebut masih belum efisien/ideal.

b. Bulan Februari angka BOR 38\%, AvLOS 8 hari, TOI 17 hari, dan BTO 1 kali. Grafik tersebut menggambarkan bahwa penggunaan tempat tidur pada bulan Februari masih belum efisien, hal ini dapat dilihat pada titik temu keempat parameter terletak di luar daerah efisien/ideal. Menurut Soejadi (1996), Sudra (2010), dan Rustiyanto (2010) apabila titik parameter pendayagunaan tempat tidur tergambar di luar daerah efisien maka penggunaan tempat tidur di rumah sakit dan pada periode tersebut masih belum efisien/ideal.

c. Bulan Maret angka BOR 43\%, AvLOS 9 hari, TOI 12 hari, dan BTO 1 kali. Grafik tersebut menggambarkan bahwa penggunaan tempat tidur pada bulan Maret masih belum efisien, hal ini dapat dilihat pada titik temu keempat parameter terletak di luar daerah efisien. Menurut Soejadi (1996), Sudra (2010), dan Rustiyanto (2010) apabila titik parameter pendayagunaan tempat tidur tergambar di luar daerah efisien maka penggunaan tempat tidur di rumah sakit dan pada periode tersebut masih belum efisien/ideal.

d. Bulan April dalam grafik tersebut menggambarkan bahwa titik keempat parameter tidak berada dalam satu titik, angka (AvLOS 6 hari dan TOI 10 hari) sedangkan (BOR 46\% dan BTO 1 kali). Menurut Soejadi (1996) salah satu fungsi dari grafik BJ adalah mengecek kebenaran suatu laporan, jadi apabila titik barber-johnson tidak berada dalam satu titik kemungkinan ada kesalahan dalam proses pembuatan pelaporan. Sedangkan menurut Sudra (2010) Jika perhitungan nilai keempat parameter tersebut benar (datanya benar, rumusnya benar, cara menghitungnya benar, dan pembulatannya benar) maka seharusnya keempat garis bantu itu akan berpotongan di satu titik.

e. Pada bulan Mei di dalam grafik tersebut menggambarkan bahwa titik keempat parameter tidak berada dalam satu titik, angka (AvLOS 7 hari dan TOI 10 hari) sedangkan (BOR 53\% dan BTO 1 kali). Menurut Soejadi (1996) salah satu fungsi dari grafik BJ adalah mengecek kebenaran suatu laporan, jadi apabila titik barber-johnson tidak berada dalam satu titik kemungkinan ada kesalahan dalam proses pembuatan pelaporan. Sedangkan menurut Sudra (2010) Jika perhitungan nilai keempat parameter tersebut benar (datanya benar, rumusnya benar, cara menghitungnya benar, dan pembulatannya benar) maka seharusnya keempat garis bantu itu akan berpotongan di satu titik.

f. Pada bulan Juni di dalam grafik tersebut menggambarkan bahwa titik keempat parameter tidak berada dalam satu titik, angka (AvLOS 7 hari dan TOI 8 hari) sedangkan (BOR 58\% dan BTO 1 kali). Menurut Soejadi (1996) salah satu fungsi dari grafik BJ adalah mengecek kebenaran suatu laporan, jadi apabila titik barber-johnson tidak berada dalam satu titik kemungkinan ada kesalahan dalam proses pembuatan pelaporan. Sedangkan menurut Sudra (2010) Jika perhitungan nilai keempat parameter tersebut benar (datanya benar, rumusnya benar, cara menghitungnya benar, dan pembulatannya benar) maka seharusnya keempat garis bantu itu akan berpotongan di satu titik.

g. Pada bulan Juli angka BOR 51\%, AvLOS 9 hari, TOI 8 hari, dan BTO 1 kali. Grafik tersebut menggambarkan bahwa penggunaan tempat tidur pada bulan Juli masih belum efisien, hal ini dapat dilihat pada titik temu keempat parameter terletak di luar daerah efisien/ideal. Menurut Soejadi (1996), Sudra (2010), dan Rustiyanto (2010) apabila titik parameter pendayagunaan tempat tidur tergambar di luar daerah efisien maka penggunaan tempat tidur di rumah sakit dan pada periode tersebut masih belum efisien/ideal.

h. Pada bulan Agustus di dalam grafik tersebut menggambarkan bahwa titik keempat parameter tidak berada dalam satu titik, angka (AvLOS 6 hari dan TOI 14 hari) sedangkan (BOR 40\% dan BTO 1 kali). Menurut Soejadi (1996) salah satu fungsi dari grafik BJ adalah mengecek kebenaran suatu laporan, jadi apabila titik barber-johnson tidak berada dalam satu titik kemungkinan ada kesalahan dalam proses pembuatan pelaporan. Sedangkan menurut Sudra (2010) Jika perhitungan nilai keempat parameter tersebut benar (datanya benar, rumusnya benar, cara menghitungnya benar, dan pembulatannya benar) maka seharusnya keempat garis bantu itu akan berpotongan di satu titik.

i. Pada bulan September di dalam grafik tersebut menggambarkan bahwa titik keempat parameter tidak berada dalam satu titik, angka (AvLOS 7 hari dan TOI 12 hari) sedangkan (BOR 43\%, dan BTO 1 kali). Menurut Soejadi (1996) salah satu fungsi dari grafik BJ adalah mengecek kebenaran suatu laporan, jadi apabila titik barber-johnson tidak berada dalam satu titik kemungkinan ada kesalahan dalam proses pembuatan pelaporan. Sedangkan menurut Sudra (2010) Jika perhitungan nilai keempat parameter tersebut benar (datanya benar, rumusnya benar, cara menghitungnya benar, dan pembulatannya benar) maka seharusnya keempat garis bantu itu akan berpotongan di satu titik. 
j. Pada bulan Oktober angka BOR 48\%, AvLOS 5 hari, TOI 6 hari, dan BTO 2 kali. Grafik tersebut menggambarkan bahwa penggunaan tempat tidur pada bulan Oktober masih belum efisien, hal ini dapat dilihat pada titik temu keempat parameter terletak di luar daerah efisien/ideal. Menurut Soejadi (1996), Sudra (2010), dan Rustiyanto (2010) apabila titik parameter pendayagunaan tempat tidur tergambar di luar daerah efisien maka penggunaan tempat tidur di rumah sakit dan pada periode tersebut masih belum efisien/ideal.

k. Pada bulan Nopember di dalam grafik tersebut menggambarkan bahwa titik keempat parameter tidak berada dalam satu titik, angka (AvLOS 8 hari dan TOI 5 hari) sedangkan (BOR 59\% dan BTO 2 kali). Menurut Soejadi (1996) salah satu fungsi dari grafik BJ adalah mengecek kebenaran suatu laporan, jadi apabila titik barber-johnson tidak berada dalam satu titik kemungkinan ada kesalahan dalam proses pembuatan pelaporan. Sedangkan menurut Sudra (2010) Jika perhitungan nilai keempat parameter tersebut benar (datanya benar, rumusnya benar, cara menghitungnya benar, dan pembulatannya benar) maka seharusnya keempat garis bantu itu akan berpotongan di satu titik.

1. Pada bulan Desember di dalam grafik tersebut menggambarkan bahwa titik keempat parameter tidak berada dalam satu titik, angka (AvLOS 7 hari dan TOI 11 hari) sedangkan (BOR 56\% dan BTO 1 kali). Menurut Soejadi (1996) salah satu fungsi dari grafik BJ adalah mengecek kebenaran suatu laporan, jadi apabila titik barber-johnson tidak berada dalam satu titik kemungkinan ada kesalahan dalam proses pembuatan pelaporan. Sedangkan menurut Sudra (2010) Jika perhitungan nilai keempat parameter tersebut benar (datanya benar, rumusnya benar, cara menghitungnya benar, dan pembulatannya benar) maka seharusnya keempat garis bantu itu akan berpotongan di satu titik.

Pendayagunaan tempat tidur di RS Lancang Kuning Pekanbaru dari bulan Januari sampai bulan Desember tahun 2011 yang tergambar dalam gambar 2 titik temu keempat parameter (BOR, AvLOS, TOI, dan BTO) pada bulan Januari, Februari, Maret, Juli, dan Oktober berada di luar daerah efisien. Menurut Sudra (2010) apabila titik temu keempat parameter tergambar di luar daerah efisien maka penggunaan tempat tidur di rumah sakit tersebut masih belum efisien dan menandakan bahwa sistem yang berjalan kurang baik.

Pada bulan April, Mei, Juni, Agustus, September, Nopember, dan Desember dalam grafik BJ gambar 2 titik keempat parameter tidak bertemu dalam satu titik melainkan terpisah. Menurut Soejadi (1996) salah satu fungsi dari grafik BJ adalah mengecek kebenaran suatu laporan, jadi apabila titik barberjohnson tidak berada dalam satu titik kemungkinan ada kesalahan dalam proses pembuatan pelaporan. Sedangkan menurut Sudra (2010) Jika perhitungan nilai keempat parameter tersebut benar (datanya benar, rumusnya benar, cara menghitungnya benar, dan pembulatannya benar) maka seharusnya keempat garis bantu itu akan berpotongan di satu titik. Hal ini diperkuat dengan temuan penulis bahwasannya sumber data dalam menghitung penggunaan tempat tidur kurang akurat.

Pihak manajemen seharusnya mengevaluasi terhadap kegiatan yang dapat mempengaruhi demand (permintaan) tempat tidur dalam periode waktu tertentu secara berkala agar bulan-bulan berikutnya menjadi naik dan akan berdampak baik pada akumulasi setiap akhir tahun. Selain itu juga unit rekam medis dan perawat ruangan harus melakukan evaluasi terhadap pencatatan mengenai penggunaan tempat tidur secara berkala.

\section{Perbandingan Tingkat Efisiensi Pendayagunaan Tempat Tidur di RS Lancang Kuning Pekanbaru Tahun 2011 Antar Ruang Rawat Inap dengan Metode Grafik BJ}

Dari hasil penelitian yang dilakukan oleh penulis di RS Lancang Kuning Pekanbaru kegiatan sensus harian pasien rawat inap tidak dilakukan oleh perawat ruangan melainkan oleh petugas rekam medis yang mendapatkan laporan dari perawat atau lebih sering dengan melihat buku register pasien masuk dan keluar yang ada di ruang rawat inap. Setelah data dari ruangan didapatkan oleh petugas rekam medis, kemudian petugas menginputnya kedalam formulir sensus. Menurut DepKes (1994) Sensus harian pasien rawat inap penanggung jawab pengisisannya dilakukan oleh perawat/bidan yang ada di ruang rawat inap terkait. Selain itu, sensus yang dibuat petugas rekam medis masih belum lengkap isinya. Sensus harian pasien rawat inap hendaknya diisi dengan lengkap karena sangat berguna untuk menghitung penggunaan tempat tidur, serta Untuk mengetahui jumlah pasien masuk dan pasien keluar rumah sakit baik dalam keadaan hidup maupun meninggal (DepKes, 1994).

Sensus harian pasien rawat inap memang harus dibuat lengkap, kerena merupakan sumber data primer dalam penghitungan dan penyajian informasi mengenai penggunaan tempat tidur. Jadi agar informasi yang dihasilkan akurat dan tepat maka mutlak apabila sumber datanya lengkap dan akurat pula. Sebaiknya ini menjadi bahan evaluasi bagi bagian pelayanan medik melalui unit rekam medis dan juga petugas perawat.

\section{KESIMPULAN}

1. Pendayagunaan tempat tidur di RS Lancang Kuning Pekanbaru (Bed Occupancy Ratio 49\%, Average Length Of Stay 8 hari, Turn Over Interval 11 hari, dan Bed Turn Over 15 kali). 
2. Tingkat efisiensi pendayagunaan tempat tidur pada tahun 2011 di RS Lancang Kuning Pekanbaru yang tergambar di grafik BJ masih belum efisien dan juga titik temu keempat parameter (BOR, AvLOS, TOI, dan BTO) tidak berada dalam satu titik, ini mengindikasikan adanya kemungkinan kasalahan pada sumber data.

3. Dari bulan Januari sampai Desember Tahun 2011 pendayagunaan tempat tidur yang tergambar di grafik BJ tiap-tiap bulannya belum ada yang mencapai efisien.

4. Sensus harian rawat inap tidak di isi oleh perawat/bidan ruangan melainkan sepenuhnya dilakukan oleh petugas rekam medis yang dibuat berdasarkan pasien masuk dan keluar dari seluruh ruangan, sehingga tidak ada laporan penggunaan tempat tidur per ruangan serta memperbesar kemungkinan ketidak akuratan data.

\section{SARAN}

1. Tingginya angka TOI dan rendahnya BTO harus mendapatkan perhatian yang serius dari pihak manajemen, agar melakukan perbaikan-perbaikan organisasi terutama bagian marketing yang dapat meningkatkan permintaan (demand) akan tempat tidur di tahun-tahun berikutnya, demi pengembangan rumah sakit masa yang akan datang.

2. Tidak bertemunya keempat parameter (BOR, AvLOS, TOI, dan BTO) di satu titik dalam grafik BJ sebaiknya menjadi bahan evaluasi bagi unit kerja rekam medis dan juga unit terkait (perawat ruangan).

3. Tiap-tiap bulan dalam tahun 2011 penggunaan tempat tidur masih belum efisien, pihak manajemen seharusnya mengevaluasi setiap periode waktu tertentu secara berkala agar dapat meningkatkan permintaan tempat tidur dari bulan ke bulan berikutnya serta efisien dari segi ekonomi dan medis.

4. Sensus harian pasien rawat inap seharusnya di isi oleh perawat/bidan yang ada di masing-masing ruangan, sehingga unit kerja rekam medis tidak double job dan dapat mempermudah dalam melakukan perhitungan penggunaan tempat tidur per ruang rawat inap. Direktur pelayanan medik seharusnya memberlakukan kebijakan mengenai sensus harian pasien rawat inap.

5. Bagi peneliti lain, disarankan meneliti mengenai kegiatan statistik pasien rawat inap agar mengetahui kemungkinan adanya kesalahan dalam pengumpulan data, pengolahan data, dan penyajian data serta melakukan penelitian mengenai faktorfaktor yang menjadi penghambat tidak berjalannya sensus harian pasien rawat inap seperti SOP, dan SDM agar dapat menemukan kendala-kendala yang dapat mempengaruhi kegiatan sensus harian pasien rawat inap.

\section{UCAPAN TERIMA KASIH}

Terima kasih kepada Bapak Nopriadi atas bimbingannya, terima kasih juga kepada Ibu Desri (Dosen) dan Manajemen RS Lancang Kuning.

\section{DAFTAR PUSTAKA}

Aditama, T.Y. (2010). Manajemen Administrasi Rumah Sakit, Universitas Indonesia, Jakarta. 6$7 \mathrm{p}$.

Brotowarsito. (2003). Peranan Rekam Medis Dalam Mendukung Kebijaksanaan Pemerintah Dalam Kaitan Rumah Sakit Sebagai Unit Swadaya. PORMIKI, 2003. Kumpulan Makalah Seminar Nasional Dalam Kongres dan Rakernas I-III PORMIKI, Jakarta. 26-27p.

Depkes RI. (1994). Buku Pedoman Pencatatan Kegiatan Pelayanan Rumah Sakit di Indonesia. Jakarta.43-63p.

Depkes RI. (2005). Buku Petunjuk Pengisian, Pengolahan, dan Penyajian Data Rumah Sakit. Jakarta. 79-94p.

Depkes RI. (2006). Pedoman Penyelenggaraan dan Prosedur Rekam Medis Rumah Sakit di Indonesia. Jakarta. 10-13p.

Notoadmodjo, S. (2005). Metodologi Penelitian Kesehatan. Jakarta : Rineka Cipta. 138-144p.

Notoadmodjo, S. (2010). Metodologi Penelitian Kesehatan. Jakarta : Rineka Cipta. 100-103p.

Rustiyanto, E. (2010). Statistik Rumah Sakit Untuk Pengambilan Keputusan. Yogyakarta : Graha Ilmu. 52-59p.

Soejadi, DHHSA. (1996). Efisiensi Pengelolaan Rumah Sakit. Jakarta : Katiga Bina. 1-26p.

Sudra, R.I. (2010). Statistik Rumah Sakit. Yogyakarta : Graha Ilmu. 39-59p. 